\title{
Antioxidant Properties and Total Phenolics of Thua Nao (a Thai Fermented Soybean) as Affected by Bacillus-fermentation
}

\author{
Katekan Dajanta ${ }^{1,2}$, Arunee Apichartsrangkoon ${ }^{1}$ and Ekachai Chukeatirote ${ }^{3, *}$
}

${ }^{1}$ Department of Food Science and Technology, Faculty of Agro-Industry, Chiang Mai University, Chiang Mai 50100, Thailand

${ }^{2}$ Faculty of Food and Agricultural Technology, Pibulsongkram Rajabhat University, Phitsanulok 65000 Thailand

${ }^{3}$ School of Science, Mae Fah Luang University, Chiang Rai 57100, Thailand

\begin{abstract}
The present study aims to investigate antioxidant activity and phenolic contents of Thai thua nao. Methanolic extracts of cooked non-fermented soybeans (CNF) and thua nao-fermented soybeans prepared by naturally occurring bacteria (TNMX) and Bacillus subtilis TN51 (TNB51) were prepared and used to determine antioxidant activities by $\beta$-carotene-linoleic acid system and DPPH-radical scavenging assay. Total phenolic contents of thua nao samples (both TNMX and TNB51) were significantly higher than those of the CNF samples (with an increase around 21 and $35 \%$, respectively). A correlation between larger amount of total phenolics and higher antioxidant activity as determined by the $\beta$-carotene-linoleic acid model was observed in these extracts. All these results indicate that production process and bacterial fermentation are responsible for improvement of total phenolics and antioxidant activity. The potential use of $B$. subtilis TN51 appears to be a suitable fermenting strain to promote antioxidant property in cooked soybean.
\end{abstract}

Keywords: Antioxidant activity; Bacillus subtilis; Fermented soybean; Phenolics; Thua nao

\section{Introduction}

Thua nao, indigenous to Thailand, is an alkaline-fermented food condiment made from soybeans. It is essential in several local recipes as flavouring agents and has long been used as an important protein source in the Northern region of Thailand. The consumption of soy-fermented foods has been shown to promote several beneficial effects on human health; these include a good source of protein and soy-isoflavones which are well known for their pharmacological and antioxidant properties [1,2]. Although known as an important source of nutritive protein, these fermented soybeans have been described to possess biological activities such as anticancer [3], antidiabetic [4], antimicrobial [5], and antioxidant activities [6]. Such activities can be described by the ability of antioxidants present in soy-fermented foods to scavenge free radicals responsible for oxidative damage of biomolecules (i.e., lipids, nucleic acids, and proteins). Recently, more and more researchers have paid a great attention to natural antioxidants of fermented soybeans $[1,2,6]$. Most of these antioxidants are poly phenolic compounds functioning as metal chelators, reducing agents, and singlet oxygen quenchers. Of these, isoflavones (i.e., genistein and daidzein) are found at high concentration and they are known to act against some diseases such as cancer [7] and atherosclerosis [8].

Several reports have found that many fermented soybean foods exhibit high contents of anti-oxidative agents than unfermented soybeans [9]. Such data have been reported and documented in various kinds of fermented soybeans such as Japanese natto [10], Korean chungkookjang [11], and Indian kinema [12]. However, antioxidative effects of Thai thua nao remain unknown although one previous report has demonstrated that aglycone amounts could be enhanced in thua nao when a pure starter culture of Bacillus species was used [13]. This present study was therefore undertaken aiming to examine antioxidative property of thua nao using $\beta$-carotene-linoleic acid system and DPPH-radical scavenging assay.

\section{Materials and Methods}

\section{Bacterial strain and culture conditions}

Bacillus subtilis TN51 previously isolated from commercial thua nao was used as pure starter culture due to its high proteolytic activity [14]. The bacteria were routinely cultured on nutrient agar and, for stock culture, the $20 \%$ glycerol bacterial culture was prepared and kept at $-20^{\circ} \mathrm{C}$. For inoculum preparation, the bacteria were grown in nutrient broth at $37^{\circ} \mathrm{C}$ for $24 \mathrm{~h}$. The cells were then harvested by centrifugation (14000 rpm, $10 \mathrm{~min}, 4^{\circ} \mathrm{C}$ ), resuspended in sterile distilled water and adjusted to $10^{4} \mathrm{CFU} / \mathrm{mL}$ using Haemocytometer slides. This cell suspension was ready to serve as inoculum for soybean fermentation.

\section{Preparation of thua nao}

Protein-rich soybeans variety TG145 obtained from the Field Crop Research Center, Institute of Agriculture, Chiang Mai, Thailand, were washed and soaked in tap water for $16 \mathrm{~h}$ at ambient temperature $\left(\sim 25^{\circ} \mathrm{C}\right)$. Before fermentation, different methods were used to prepare cooked non-fermented soybeans (CNF). Soaked soybeans were cooked by boiling for $4 \mathrm{~h}$ (CNF1) and left to ferment by naturally occurring microbes (TNMX). In contrast, for Bacillus-inoculum fermentation, soaked soybeans were sterilised at $121^{\circ} \mathrm{C}$ for $40 \mathrm{~min}(\mathrm{CNF} 2)$, and inoculated with $10^{4} \mathrm{CFU}$ (per g of sterilised soybeans) of B. subtilis TN51 starter culture (TNB51). Fermentation process was then allowed to proceed at $42^{\circ} \mathrm{C}$ for $72 \mathrm{~h}$. At the end of the fermentation period, all $\mathrm{CNF}$ and fermented soybean samples were smashed, freeze-dried by a lyophiliser (Labconco, USA), and stored in airtight bottles at $-18^{\circ} \mathrm{C}$ until analysis.

\section{Preparation of methanol extracts of thua nao}

Based on the procedure of Lee et al. [15], the ground powder of

*Corresponding author: Ekachai Chukeatirote, School of Science, Mae Fah Luang University, Chiang Rai 57100, Thailand, E-mail: ekachai@mfu.ac.th

Received February 24, 2011; Accepted June 16, 2011; Published June 22, 2011

Citation: Dajanta K, Apichartsrangkoon A, Chukeatirote E (2011) Antioxidant properties and total phenolics of thua nao (a Thai fermented soybean) as affected by Bacillus-fermentation. J Microbial Biochem Technol 3: 056-059. doi:10.4172/19485948.1000052

Copyright: @ 2011 Dajanta K, et al. This is an open-access article distributed unde the terms of the Creative Commons Attribution License, which permits unrestricted use, distribution, and reproduction in any medium, provided the original author and source are credited 
the lyophilised sample $(30 \mathrm{~g})$ was extracted with $300 \mathrm{~mL}$ of $80 \%(\mathrm{v} / \mathrm{v})$ methanol for $16 \mathrm{~h}$ at room temperature with continuous shaking. The extracts were filtered through Whatman No.1 paper, concentrated under vacuum at $40^{\circ} \mathrm{C}$ and freeze-dried. The lyophilized extracts were stored at $4^{\circ} \mathrm{C}$ and, before use; the extracts were dissolved in methanol.

\section{Assay of total phenolics}

Total phenolics were analysed using the protocol of Lin et al. [16]. The methanolic extract solution $(0.1 \mathrm{~mL})$ was added to a mixture of 1.9 $\mathrm{mL}$ of deionised water and $1 \mathrm{~mL}$ of Folin-Ciocalteu phenol reagent. After $8 \mathrm{~min}$ incubation at room temperature, $5 \mathrm{~mL}$ of $20 \%(\mathrm{w} / \mathrm{v})$ sodium carbonate were added and this mixture was then heated in a boiling water bath $\left(\sim 95^{\circ} \mathrm{C}\right)$ for $1 \mathrm{~min}$. The absorbance was measured at $750 \mathrm{~nm}$ by a spectrophotometer and the results expressed in $\mathrm{mg}$ of gallic acid per gram extract. Gallic acid $(0-1 \mathrm{mg} / \mathrm{ml})$ was used in this study for the standard calibration curve.

\section{$\beta$-carotene-linoleate model assay}

The antioxidant activity of sample extracts was determined using the $\beta$-carotene linoleic acid model system [17]. A solution of $\beta$-carotene was prepared by dissolving $2 \mathrm{mg}$ of $\beta$-carotene in $10 \mathrm{~mL}$ of chloroform. Two milliliters of this solution were transferred into a $100 \mathrm{~mL}$ roundbottom flask. After the chloroform was removed under vacuum, $40 \mathrm{mg}$ of purified linoleic acid, $400 \mathrm{mg}$ of Tween 40 emulsifier, and $100 \mathrm{~mL}$ of aerated distilled water were added to the flask with vigorous shaking. This emulsion $(4.8 \mathrm{~mL})$ was aliquoted into $0.2 \mathrm{~mL}$ of $10 \mathrm{mg} / \mathrm{mL}$ sample extract. For control, $80 \%$ methanol was used in the reaction instead of the sample extracts. The mixture was then shaken and stored at $50^{\circ} \mathrm{C}$ for $2 \mathrm{~h}$. The absorbance of the samples was measured at $470 \mathrm{~nm}$ at the beginning $(0 \mathrm{~min})$ and at the end of the experiment $(120 \mathrm{~min})$. Antioxidant activity was then calculated using the following equation: $\%$ Antioxidant activity $=100 \times\left[1-\left\{\left(\mathrm{A}_{\mathrm{so}}-\mathrm{A}_{\mathrm{se}}\right) /\left(\mathrm{A}_{\mathrm{co}}-\mathrm{A}_{\mathrm{ce}}\right)\right\}\right]$ where $\mathrm{A}_{\mathrm{so}}$ and $A_{\text {se }}$ were absorbance of the sample at 0 and $120 \mathrm{~min}$, and $A_{c o}$ and $\mathrm{A}_{c e}$ were absorbance of the control at 0 and 120 min [17].

\section{Determination of DPPH radical-scavenging activity}

Antioxidant activity of the extracts was determined using the stable free radical 2, 2-diphenyl-1-picrylhydrazyl (DPPH) method [18]. One millilitre of methanolic lyophilized extracts $(1-20 \mathrm{mg} /$ $\mathrm{mL}$ ) was added to $2.0 \mathrm{~mL}$ of $75 \mathrm{mM}$ methanolic solution of DPPH. The mixture was shaken and allowed to stand in the dark at room temperature for $5 \mathrm{~min}$. The decrease in absorbance at $517 \mathrm{~nm}$ was then measured against methanol. The inhibitory percentage of DPPH was calculated according to the equation as follows: \% scavenging activity $=[1-(\mathrm{As} / \mathrm{Ac})] \mathrm{x} 100$; where As and Ac were the absorbance values at $517 \mathrm{~nm}$ of the DPPH solutions with sample and without sample (control), respectively [18]. The percentage of scavenging activity obtained was subsequently plotted against the sample concentration. The half maximal inhibitory concentration $\left(\mathrm{IC}_{50}\right)$ was then calculated from the equation analyzed from the logarithmic regression between sample concentration and inhibition rate. In addition, the efficient concentration representing amount of antioxidant required to decrease the initial DPPH concentration by $50 \%\left(\mathrm{EC}_{50}\right)$ was calculated from the following formula: $\mathrm{EC}_{50}=\mathrm{IC}_{50} /[\mathrm{DPPH}]$ in $\mathrm{mg} / \mathrm{mL}$. The antiradical power (ARP) describing the effectiveness of antioxidant and radical scavenging capacity was also determined as follows: $\mathrm{ARP}=1 /\left(\mathrm{EC}_{50} \mathrm{x}\right.$ 100) [19].

\section{Statistical analysis}

Data were expressed as means \pm standard deviation of triplicate observations. The data were also subjected to analysis of variance (ANOVA), $t$-test, and Duncan's multiple range test (DMRT). Differences between means at $5 \%(P<0.05)$ were regarded as significant.

\section{Results and Discussion}

\section{Extraction yield}

Earlier reports on phenolic contents and antioxidant activity of plants have been based on solvent extraction. For soy-fermented food, methanol was found to be the most suitable solvent used for extracting antioxidant components [20]. In addition, the methanolic extract was also reported to exhibit higher antioxidant activity than that of other extracts in several model systems [21]. This present study thus employed this solvent and extraction yield of the CNF and thua nao samples is shown in Table 1. When using methanol, antioxidants could be extracted and accounted for 12.22 to $17.97 \%$ of lyophilized soybean tested samples (Table 1). There was no significant difference $(P>0.05)$ in the extraction yield between the CNF1 and CNF2 samples. It should be noted, however that there was a significant increase $(P<0.05)$ of the extraction yield of both thua nao samples (TNMX and TNB51). This implied that there was a bioconversion of some materials in soybeans after bacterial fermentation and the use of methanol was able to extract more soluble compounds from fermented soybeans.

\section{Total phenolics content}

Total phenolic content, expressed as mg of gallic acid equivalents (GAEs) per g of extract, was also shown in Table 1. There was no significant difference $(P>0.05)$ in amounts of phenolic compounds between the CNF samples which were 27.67 and $29.03 \mathrm{mg}$ GAEs/g extract. However, the increase of phenolic contents was observed in thua nao extracts ranging from $21-35 \%$ as compared with the original concentrations of the CNF samples. The amount of phenolic compounds in the TNMX extracts was highest $(37.29 \mathrm{mg} / \mathrm{g})$, and followed by the TNB51 extracts $(35.18 \mathrm{mg} / \mathrm{g})$. Such an increase of total phenolic contents in soybeans after fermentation as shown in this

\begin{tabular}{|l|l|l|l|}
\hline Sample & Yield of extract (\%) & $\begin{array}{l}\text { Total phenolics } \\
\text { (mg GAE/g ext.) }\end{array}$ & Phenolics/Yield of extract (\%) \\
\hline Natural fermentation & & & \\
\hline CNF1 & $12.22 \pm 0.30 \mathrm{~b}$ & $27.67 \pm 1.41 \mathrm{c}$ & $2.77 \pm 0.14 \mathrm{c}$ \\
\hline TNMX & $17.97 \pm 0.85 \mathrm{a}$ & $37.29 \pm 1.00 \mathrm{a}$ & $3.73 \pm 0.10 \mathrm{a}$ \\
\hline Pure culture fermentation & & & \\
\hline CNF2 & $12.63 \pm 1.93 \mathrm{~b}$ & $29.03 \pm 0.14 \mathrm{c}$ & $2.90 \pm 0.01 \mathrm{c}$ \\
\hline TNB51 & $16.53 \pm 0.29 \mathrm{a}$ & $35.18 \pm 1.03 \mathrm{~b}$ & $3.52 \pm 0.10 \mathrm{~b}$ \\
\hline
\end{tabular}

*Data are means \pm S.D. of triplicate measurements. Means in the same column with different letters were significantly different $(P<0.05)$.

${ }^{*}$ CNF1, CNF2 = Cooked non-fermented soybeans prepared by boiling and autoclaving, respectively; TNMX, TNB51 = thua nao fermented by naturally occurring bacteria and $B$. subtilis TN51.

Table 1: Yield (\%) and total phenolics (mg GAE/g extract) of methanolic extracts of cooked non-fermented soybeans (CNF) and thua nao. 


\begin{tabular}{|l|l|l|l|l|}
\hline Sample & AOX (\%) & \multicolumn{3}{l|}{ Free radical scavenging activity } \\
\cline { 3 - 4 } & & & \multicolumn{2}{|l|}{ EC $_{50}$} \\
\hline Natural fermentation & & $3.37 \pm 0.05 \mathrm{~b}$ & $113.93 \pm 1.82 \mathrm{~b}$ \\
\hline CNF1 & $54.55 \pm 1.16 \mathrm{~d}$ & $5.18 \pm 0.43 \mathrm{a}$ & $175.28 \pm 14.54 \mathrm{a}$ \\
\hline TNMX & $65.65 \pm 0.39 \mathrm{a}$ & & \\
\hline Pure culture fermentation & & $2.70 \pm 0.01 \mathrm{c}$ & $9.88 \pm 0.01 \mathrm{~b}$ \\
\hline CNF2 & $58.49 \pm 2.30 \mathrm{c}$ & $3.27 \pm 0.01 \mathrm{bc}$ & $11.30 \pm 0.40 \mathrm{c}$ \\
\hline TNB51 & $62.12 \pm 0.95 \mathrm{~b}$ & $1.10 \pm 0.00 \mathrm{a}$ & $0.41 \mathrm{bc}$ \\
\hline
\end{tabular}

*Data are means \pm S.D. of triplicate measurements. Means in the same column with different letters were significantly different $(P<0.05)$.

${ }^{* *}$ CNF1, CNF2 = Cooked non-fermented soybeans prepared by boiling and autoclaving, respectively; TNMX, TNB51 = thua nao fermented by naturally occurring bacteria and $B$. subtilis TN51.

${ }^{* * \star} \mathrm{AOX}=$ Antioxidant activity determined by the $\beta$-carotene linoleic acid system at $10 \mathrm{mg} / \mathrm{mL}$ of dried sample extracts; $\mathrm{IC}_{50}=\mathrm{Half}_{\mathrm{maximal}}$ inhibitory concentration $(\mathrm{mg} /$ $\mathrm{mL}$ of sample extract); $\mathrm{EC}_{50}=$ Efficiency concentration $(\mathrm{mg} / \mathrm{mg}$ DPPH); ARP = antiradical power.

Table 2: Antioxidant activities of methanolic extracts of cooked non-fermented soybeans (CNF) and thua nao.

study is in agreement with the findings of other researchers [12,16,22]. These studies also suggest that $\beta$-glucosidase, which produced from fermenting bacteria plays a key role in increasing phenolic contents of the products. Different scenario was reported however by Shon et al. [17] in which there was no change in total phenolics contents between chungkukjang and cooked non-fermented soybeans.

\section{Antioxidant activity}

In this study, antioxidant property was assessed by two different assays: $\beta$-carotene-linoleate system and DPPH free radical scavenging. For $\beta$-carotene-linoleate system, free radicals yielded from linoleic acid oxidation attack unsaturated $\beta$-carotene molecules. As a result, the existence of different antioxidants can prevent the degree of $\beta$-carotene bleaching by neutralising the linoleate-free radicals [23]. As shown in Table 2, the antioxidant activity (AOX) of the thua nao extracts was higher than that of the CNF samples. It should be noted interestingly that the AOX of the TNMX sample was highest, followed by the TNB51, CNF2 and CNF1 samples. In general, the AOX values are very high ranging from $54.55-65.65 \%$. The marked increase in the AOX values of the thua nao extracts is of great interest representing more than $62 \%$. These values, albeit used at low concentration of the extracts $(10 \mathrm{mg} / \mathrm{mL})$, are much higher than those of kinema (44\%) described by Moktan et al. [12]. It is understandable that many factors such as soybean variety, cooking process, and fermenting starter culture(s) could affect these results $[12,17]$.

Alternatively, the DPPH free radical scavenging, one of the widely used methods in antioxidative assay was also used in this study. The DPPH radical is stable and can easily accept an electron or hydrogen radical into a stable molecule. This technique can be used to evaluate the antioxidant activity of specific compounds or extracts by measuring the change of absorbance at $517 \mathrm{~nm}$ in a short time. Table 2 shows the antioxidant activities evaluated in terms of inhibitory concentration $\left(\mathrm{IC}_{50}\right)$, efficiency concentration $\left(\mathrm{EC}_{50}\right)$, and anti-radical power (ARP). The lower the $\mathrm{IC}_{50}$ and $\mathrm{EC}_{50}$, the higher the antioxidant capacity. In contrast, the ARP was calculated from the $\mathrm{EC}_{50}$; the larger the ARP, the more efficient the antioxidant activity. Based on the DPPH assay, it was found that the CNF samples exhibited higher antioxidative activity than the thua nao samples. Considered from the ARP values, the antioxidant activity of these extracts tested are as follows: CNF2 > TNB51 $>$ CNF1 $>$ TNMX.

It has previously been reported that the antioxidant activity is well correlated with the phenolic contents [24]. In the present study, it is worth noting that such a relationship has also been observed but only for the antioxidant activity determined by $\beta$-carotene bleaching model. The DPPH assay gave a different result in which the CNF samples showed higher antioxidant activity although they contained less phenolic contents. One possible explanation is due to high contents of aglycone compounds in fermented soybeans. Aglycones (i.e., daidzein and genistein) are described as inactive substrates in radical scavenging assay [25].

In addition to phenolic content, antioxidant activity can be resulted from synergistic effects of other antioxidant components such as oligoproteins, free amino acids and melanoidins as previously described in soy-fermented foods [26,27]. Peptides and free amino acids are also known as source of the anti-free radicals and anti-linoleic acid oxidation in Chinese douchi [28]. In our present study, the ratio between total polyphenolics and total extractable substances in all soybean samples ranged from 2.77 to $3.73 \%$ (Table 1) which implies that there exists a significant amount of other antioxidants apart from phenolic compounds.

\section{Conclusion}

Our study clearly showed that the methanolic extracts of cooked non-fermented soybeans and their fermented counterparts (thua nao) exhibited antioxidant and free radical scavenging properties. It was also found that there was a strong relationship between total phenolic contents and antioxidant activity (as determined by the $\beta$-carotenelinoleate method). Moreover, the use of B. subtilis TN51 appears to enhance phenolic amounts and increase antioxidant activity although data of free radical scavenging assay were inconsistent. From our results, it can be concluded that production process and bacterial fermentation play the key role in improving these properties. Further study on (bio) chemical characteristics of these antioxidative components as well as their metabolic biotransformation remains to be investigated.

\section{Acknowledgements}

This study was financially supported by the Royal Golden Jubilee Ph.D. Research Scholarship and the Thailand Research Fund.

\section{References}

1. Li LT, Yin LJ, Saito M (2004) Function of traditional foods and food culture in China. JARQ 38: 213-220.

2. Messina MJ (1999) Legumes and soybeans: overview of their nutritiona profiles and health effects. Am J Clin Nutr 70: 439-450.

3. Barnes S, Sfakianos J, Coward L, Kirk M (1996) Soy isoflavonoids and cancer prevention. Underlying biochemical and pharmacological issues. Adv Exp Med Biol 401: 87-100.

4. Kim JI, Kang MJ, Kwon TW (2003) Antidiabetic effect of soybean and Chongkukjang. Korea Soybean Digest 20: 44-52.

5. Kim Y, Cho JY, Kuk JH, Moon JH, Cho Jl, et al. (2004) Identification and antimicrobial activity of phenylacetic acid produced by Bacillus licheniformis isolated from fermented soybean. Curr Microbiol 48: 312-317. 
Citation: Dajanta K, Apichartsrangkoon A, Chukeatirote E (2011) Antioxidant properties and total phenolics of thua nao (a Thai fermented soybean) as affected by Bacillus-fermentation. J Microbial Biochem Technol 3: 056-059. doi:10.4172/1948-5948.1000052

6. Yang JH, Mau JL, Ko PT, Huang LC (2000) Antioxidant activity and active compounds of fermented soybean broth. Food Chem 71: 249-254.

7. Head K (1997) Isoflavones and other soy constituents in human health and disease. Alternative Med Rev 2: 433-450.

8. Kirk EA, Sutherland P, Wang SA, Chait A, LeBoeuf RC (1998) Dietary isoflavones reduce plasma cholesterol and atherosclerosis in C57BL/6 mice but not LDL receptor-deficient mice. J Nutr 128: 954-959.

9. Fukushima D (2001) Recent progress in research and technology on soybean Food Sci Technol Res 7: 8-16.

10. Hattori T, Ohishi H, Yokota T, Ohoami H, Watanabe K (1995) Antioxidative effect on crude antioxidant preparation from soybean fermented by Bacillus natto. LWT-Food Sci Technol 28: 135-138.

11. Kwak CS, Lee MS and Park SC (2007) Higher antioxidant properties of Chungkookjang, a fermented soybean paste, may be due to increase aglycone and malonylglycoside isoflavone during fermentation. Nutr Res 27: 719-727.

12. Moktan B, Saha J and Sarkar K (2008) Antioxidant activities of soybean as affected by Bacillus-fermentation of kinema. Food Res Int 41: 586-593.

13. Dajanta K, Chukeatirote E, Apichartsrangkoon A and Frazier RA (2009) Enhanced aglycone production of fermented soybean products by Bacillus species. Acta Biol Szeged 53: 93-98.

14. Dajanta K, Wongkham S, Thirach $P$, Baophoeng $P$, Apichartsrangkoon A, et al.(2009) Comparative study of proteolytic activity of protease-producing bacteria isolated from thua nao. Maejo Int J Sci Technol 3: 269-276.

15. Lee IH, Hung YH and Chou CC (2007) Total phenolic and anthocyanin contents, as well as antioxidant activity of black bean koji fermented by Aspergillus awamori under different culture conditions. Food Chem 104: 936-942.

16. Lin CH, Wei YT and Chou CC (2006) Enhanced antioxidant activity of soybean koji prepared with various filamentous fungi. Food Microbiol 23: 628-633.

17. Shon MY, Lee J, Choi JH, Choi SY, Nam SH, et al. (2007) Antioxidant and free radical scavenging activity of methanol extract of chungkukjang. J Food Compos Anal 20: 113-118.

18. Yun IS (2005) Antibacterial, free radical scavenging,and proliferative effects of
Korean fermented soybean paste (Doenjang) extracts. Agric Chem Biotechnol 48: $138-143$

19. Prakash D, Upadhyay G, Singh BN and Singh HB (2007) Antioxidant and free radical-scavenging activities of seeds and agri-waste of some variety of soybean (Glycine max). Food Chem 104: 783-790.

20. Esaki H, Onozaki H, Kawakishi S and Osawa T (1997) Antioxidant activity and isolation from soybeans fermented with Aspergillus spp. J Agric Food Chem 45: 2020-2024.

21. Chyau CC, Tsai SY, Ko PT, Mau JL (2002) Antioxidant properties of solvent extracts from Terminalia catappa leaves. Food Chem 78:483-488

22. Georgetti SR, Vicentini FTMC, Yokoyama CY, Borin MF, Spadaro ACC, et al (2009) Enhanced in vitro and in vivo antioxidant activity and mobilization of free phenolic compounds of soybean flour fermented with different b-glucosidaseproducing fungi. J Appl Microbiol 106:459-466.

23. Jayaprakasha GK, Singh RP, Sakariah KK (2001) Antioxidant activity of grape seed (Vitis vinifera) extracts on peroxidation models in vitro. Food Chem 73:285-290

24. Velioglu YS, Mazza G, Gao L, Oomah BD (1998) Antioxidant activity and tota phenolics in selected fruits, vegetables, and grain products. J Agric Food Chem 46: 4113-4117.

25. Mitchell JH, Gardner PT, McPhail DB, Morrice PC, Collins AR, et al. (1998) Antioxidant efficacy of phytoestrogens in chemical and biological mode systems. Arch Biochem Biophys 360: 142-148.

26. Delgado-Andrade C, Morales FJ ( 2005) Unraveling the contribution of melanoidins to the antioxidant activity of coffee brews. J Agric Food Chem 53:1403-1407

27. Saito K, Jin DH, Ogawa T, Muramoto K, Hatakeyama E, et al. (2006) Antioxidative properties of tripeptide libraries prepared by the combinatorial chemistry. J Agric Food Chem 51:3668-3674.

28. Wang D, Wang LJ, Zhu FX, Zhu JY, Chen XD, et al. (2008) In vitro and in vivo studies on the antioxidant activities of the aqueous extracts of Douchi (a traditional Chinese salt-fermented soybean food). Food Chem 107:1421-1428. 